\title{
The Hunsaker Mon-Jet tube with jet ventilation is effective for microlaryngeal surgery
}

\section{La sonde de ventilation en jet Hunsaker Mon-Jet est efficace dans les microchirurgies laryngées}

\author{
Joanna M. Davies, FRCA · Allen D. Hillel, MD • \\ Nicole C. Maronian, MD · Karen L. Posner, PhD
}

Received: 5 September 2008/Revised: 14 January 2009/Accepted: 20 January 2009/Published online: 25 February 2009

(C) Canadian Anesthesiologists' Society 2009

\begin{abstract}
Purpose Microlaryngeal surgery involves a delicate balance between airway control and appropriate visualization of laryngeal anatomy. When the self-centering, laser-safe Hunsaker Mon-Jet tube (Xomed, Jacksonville, FL) was introduced in 1994, to provide subglottic ventilation, the needs of both anesthesiologist and surgeon appeared to have been adequately met. However, limited data exists regarding the efficacy of this device in a large patient series. The aim of this cohort study was to explore the spectrum of patients and procedures for which this technique could be used.

Methods We report a retrospective study of 552 patients who had undergone microlaryngeal surgery between January 1995 and June 2005, utilizing the Hunsaker Mon-Jet tube and automated jet ventilator to provide subglottic ventilation. In addition to patient demographics, overall success of ventilation and several perioperative outcomes were evaluated, including the incidence of complications. Results In combination with an automatic jet ventilator, the Hunsaker Mon-Jet tube was successfully utilized in more than $98 \%$ of the 552 patients, including those with
\end{abstract}

J. M. Davies, FRCA ( ()$\cdot$ K. L. Posner, PhD

Department of Anesthesiology and Pain Medicine, University

of Washington Medical Center, Box 356540, Seattle,

WA 98195-6540, USA

e-mail: jodavies@u.washington.edu

A. D. Hillel, MD

Department of Otolaryngology, University of Washington

Medical Center, Seattle, WA, USA

N. C. Maronian, MD

Department of Otolaryngology-HNS, University Hospitals Case

Western Reserve Medical Center, Cleveland, OH, USA severe co-morbidities, obesity and difficult airway access, providing optimal visualization of the vocal cords and excellent surgical access for a wide range of laryngeal disorders, including laser treatment. In less than $2 \%$ of patients, hypoxia, hypercarbia, or both, necessitated exchange of the Hunsaker Mon-Jet tube for a standard or laser-safe endotracheal tube with rapid resolution of the precipitating cause.

Conclusions Subglottic ventilation via the Hunsaker Mon-Jet tube with an automated jet ventilator may be considered an effective, safe and versatile technique for the anesthetic management of microlaryngeal surgery.

\section{Résumé \\ Objectif Pour réaliser une microchirurgie laryngée, il faut atteindre un équilibre délicat entre le contrôle des voies aériennes et une visualisation adéquate de l'anato- mie du larynx. Lors de l'introduction en 1994 de la sonde Hunsaker Mon-Jet (Xomed, Jacksonville, FL), un dispositif résistant au laser et à centrage automatique, destiné à procurer une ventilation sous-glottique, il semblait que les besoins de l'anesthésiologiste et du chirurgien étaient comblés. Toutefois, nous ne disposons que d'une quantité limitée de données concernant l'efficacité de ce dispositif dans une importante série de patients. L'objectif de cette étude de cohorte était d'explorer l'éventail de patients et d'interventions pour lesquels cette technique pouvait être utilisée.}

Méthode Nous rapportons une étude rétrospective portant sur 552 patients ayant subi une microchirurgie laryngée entre janvier 1995 et juin 2005 et pour lesquels la sonde Hunsaker Mon-Jet et un ventilateur par jet automatique ont été utilisés pour la ventilation sous-glottique. Outre les données démographiques concernant les patients, le succès global de la ventilation et plusieurs devenirs 
périopératoires ont été évalués, notamment l'incidence de complications.

Résultats Lorsqu'elle est utilisée conjointement avec un ventilateur par jet automatique, la sonde Hunsaker MonJet a été efficace chez plus de $98 \%$ des 552 patients, y compris les patients présentant des co-morbidités graves, les patients obèses ou ceux présentant un accès difficile aux voies aériennes. La sonde a procuré une visualisation optimale des cordes vocales ainsi qu'un excellent accès chirurgical dans un large éventail de troubles laryngés, notamment dans les traitements au laser. Chez moins de 2 $\%$ des patients, une hypoxie, une hypercapnie, ou l'apparition de ces deux complications, ont nécessité d'échanger la sonde Hunsaker Mon-Jet contre une sonde endotrachéale standard ou résistante au laser, ce qui a permis une résolution rapide des complications.

Conclusion La ventilation sous-glottique avec la sonde Hunsaker Mon-Jet combinée à un ventilateur par jet automatique peut être considérée comme une technique efficace, sécuritaire et polyvalente pour la prise en charge anesthésique de la microchirurgie laryngée.

Microlaryngeal surgical techniques and equipment have shown consistent and ongoing advancement. The laryngologist focuses on the optimal operating laryngoscope for visualization and surgical access, while the anesthesiologist is concerned with ventilation and control of the airway with less regard for the way in which the larynx will be visualized around the endotracheal tube. Since the airway is shared by both the surgeon and the anesthesiologist in microlaryngeal surgery, these two disparate concerns must be resolved.

In the early $1970 \mathrm{~s}$, jet ventilation, which Sanders ${ }^{1}$ had successfully introduced in 1967 for use during bronchoscopy, was investigated as an alternative to conventional ventilatory techniques for microlaryngoscopy. ${ }^{2}$ With passive exhalation, air was jetted into the trachea from above the vocal cords through an injector cannula attached to the laryngoscope. This allowed for an unobstructed view of the larynx but no control of the airway and, as was later described, was not without complications. This technology has since been adapted to provide supraglottic, subglottic, and transtracheal jet ventilation for laryngeal surgery using a variety of laryngoscope attachments, subglottic and transtracheal catheters, and varied frequencies of ventilation. ${ }^{3,4}$ There has been considerable debate regarding the combination of these ventilatory techniques and devices that provides the best operative visualization and access, utmost airway control, and optimal ventilation. ${ }^{3,5-8}$

In 1994, Hunsaker introduced a self-centering fluoroplastic laser-safe subglottic tube through which airway pressures and end-tidal $\mathrm{CO}_{2}\left(\mathrm{ETCO}_{2}\right)$ could be monitored. Driven by a dedicated automatic jet ventilator, this tube was specifically designed for use in laryngeal surgery and overcame many of the limitations of other devices. ${ }^{3}$ In a limited series of 36 patients, the Hunsaker Mon-Jet tube with automatic jet ventilator introduced the combination of excellent visualization with anesthetic safety. ${ }^{9}$ Our study is a retrospective review of 552 patients who underwent microlaryngeal surgery with subglottic ventilation using a Hunsaker Mon-Jet tube (Xomed, Jacksonville, FL, USA) in conjunction with an automated jet ventilator. Many of these patients had substantially abnormal airway anatomy, resulting in both anticipated and unanticipated difficult intubations. In order to evaluate and demonstrate the suitability, versatility, and safety of subglottic ventilation using a Hunsaker Mon-Jet tube in conjunction with an automated jet ventilator in this unique patient population, we examined patient demographics, range of pre-operative diagnoses, procedures performed (with and without laser), as well as perioperative complications.

\section{Methods}

After obtaining Institutional Review Board Approval (\#059315-E/A 01), a 10-year (1995-2005) retrospective review was carried out involving patients who had been ventilated through a Hunsaker Mon-Jet tube for microlaryngeal surgery at the University of Washington Medical Center. We combined an anesthesia billing database, which coded for patients who had been tracheally intubated with a Hunsaker Mon-Jet tube, with a Voice Disorders Clinic database, which identified Current Procedural Terminology (CPT) codes/surgical procedures for which a Hunsaker Mon-Jet tube might have been used. There were no exclusion criteria. Two of the authors reviewed individual patient records, including preoperative anesthesia assessments, handwritten anesthesia records, and surgical notes, for patient demographics, laryngeal diagnosis, surgical CPT code, anesthetic parameters, and use of a laser. The intraoperative complications evaluated included the need to change to a standard or laser endotracheal tube (ETT), hypoxia, hypercarbia, airway obstruction, barotrauma, submucosal injection of air, tube ignition, seeding of blood into the trachea, and neurological and vascular complications. The same authors reviewed post anesthesia care unit (PACU) records for cardiovascular adverse events and for the need for tracheal reintubation or other postoperative respiratory complications, such as stridor, shortness of breath, hypoxia, and/or subcutaneous emphysema suggestive of barotrauma.

Preoperatively, intravenous antibiotics were administered to all patients, and intravenous dexamethasone was 
administered to all but those with vocal cord papillomas. Patients typically received an intravenous induction. In cases where there was concern regarding airway narrowing or potential obstruction, an inhalational induction was performed. Anesthesia was maintained with total intravenous anesthesia (TIVA) using a propofol infusion and either fentanyl boluses or a remifentanil infusion. Neuromuscular relaxation was achieved using succinylcholine boluses, a succinylcholine infusion, or a non-depolarizing agent, most commonly vecuronium. Intubation with a Hunsaker Mon-Jet tube was conducted under direct visualization by either the anesthesiologist or the laryngologist, depending on the ease of visualization and the severity of laryngeal pathology. All patients had standard American Society of Anesthesiologists (ASA) monitoring with neuromuscular function monitoring, and bispectral index (BIS) monitoring available for use at the discretion of the anesthesiologist.

The Hunsaker Mon-Jet tube is $35.5 \mathrm{~cm}$ long with a maximum outer diameter of $4.3 \mathrm{~mm}$ and an inner diameter of $2.7 \mathrm{~mm}$. The tube is made of a nonflammable fluoroplastic material rendering it laser-safe (Fig. 1). A metal stylet provides the rigidity, yet flexibility, to facilitate tracheal intubation. The basket at the distal end self-centres the tube within the trachea, preventing the jet port from coming into contact with the mucosa. A monitoring port with a $1 \mathrm{~mm}$ inner diameter opens $3.2 \mathrm{~cm}$ above the jet port and is attached proximally to a Luer-Loc adapter and a three-way stopcock.

Subglottic ventilation was provided via an automatic Acutronic AMS $1000^{1}$ (Susquehanna Micro, Red Lion, PA, USA) or an Acutronic Monsoon ${ }^{\circledR}$ jet ventilator (Susquehanna Micro, Red Lion, PA, USA) attached to the Hunsaker Mon-Jet tube. The automatic jet ventilator is attached to the jet port to provide ventilation and is connected to the monitoring port via the three-way stopcock for continuous measurement of airway pressure and intermittent monitoring of $\mathrm{ETCO}_{2}$. To reduce the risk of barotraumas, automatic shutdown of the ventilator is triggered if the airway pressures exceed preset limits. Inspired oxygen was reduced to $\leq 40 \%$, wet drapes were placed around the patient's head and face, and safety glasses were worn by all the staff in the operating room during utilization of the $\mathrm{CO}_{2}$ laser. Whether under deep anesthesia or awake, the patient's trachea was extubated at the end of the procedure when adequate spontaneous ventilation had been re-established. In addition to standard postoperative care, all patients received humidified oxygen in the post anesthesia care unit (PACU). Any complications encountered

\footnotetext{
${ }^{1}$ The Acutronic AMS 1000 \& Monsoon $^{\circledR}$ jet ventilators are manufactured in Switzerland and distributed in North America by Susquehanna Micro.
}

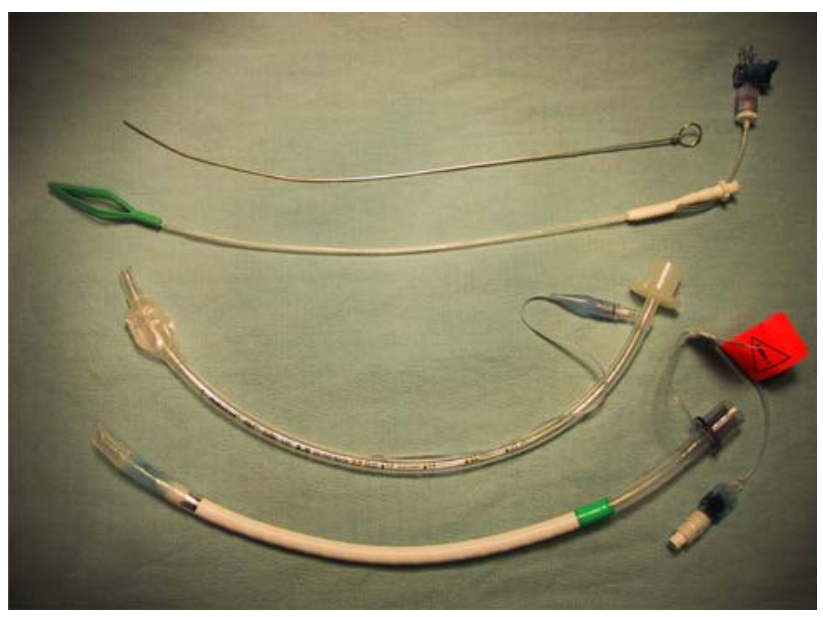

Fig. 1 Bottom to top: laser-safe endotracheal tube, microlaryngeal tube, Hunsaker Mon-Jet tube, metal stylet for a Hunsaker Mon-Jet tube

during the procedure were recorded, with particular regard for tube exchange, hypoxia, and hypercarbia. Hypoxia was defined as oxygen saturations of $<90 \%$; hypercarbia was defined as an $\mathrm{ETCO}_{2}$ of $>60 \mathrm{mmHg}$.

For all cases, the laryngologists used Dedo, Universal Modular, Lindholm, or Jackson Anterior Commissure laryngoscopes.

\section{Results}

Nearly two-thirds of the 552 patients were male and $19 \%$ were obese (Table 1). The majority of patients were ASA Physical Status II. Preoperative comorbidities included lung and heart disease, but specific diagnoses and severity of illness were not systematically documented.

Seventy-five percent of the cases involved benign and malignant vocal cord lesions managed with micro-direct laryngoscopy (micro DL) and excision of lesions. Vocal cord immobility (partial or complete, unilateral or bilateral), subglottic and laryngeal stenosis, and supraglottic malignant lesions accounted for the remaining 25\% of cases, which were managed with a combination of micro DL, lesion excision, arytenoidectomy, and vocal cord injection. Duration of surgery ranged from 4 to $240 \mathrm{~min}$ $(4 \mathrm{~h})$ with a mean of $55 \mathrm{~min}$.

Forty-six percent of the patients demonstrated a Mallampati Class I view on airway evaluation. Furthermore, by using the Cormack-Lehane grading system ${ }^{10}$ to complete laryngoscopic visualization, the anesthesiologist determined $44 \%$ of patients as being Grade I (Fig. 2). A much smaller proportion of patients were found to have more challenging or difficult intubations (Grade II to IV) (Fig. 2). Jet ventilation varied considerably between 
Table 1 Patient and case characteristics $(n=552)$

\begin{tabular}{lr}
\hline Age in years: mean (SD) & $48(17)$ \\
Duration of case in minutes: mean (SD) & $55(31)$ \\
Use of laser in cases: $n(\%)$ & $282(51)$ \\
Gender $n(\%)$ & \\
$\quad$ Male & $348(63)$ \\
$\quad$ Female & $204(37)$ \\
ASA physical status: $n(\%)$ & $112(20)$ \\
$\quad$ ASA 1 & $343(62)$ \\
$\quad$ ASA 2 & $94(17)$ \\
ASA 3 & $3(0.5)$ \\
$\quad$ ASA 4 & \\
Obesity & $92(18)$ \\
Obese BMI $\geq 30: n(\%)$ & $7(1)$ \\
Morbidly obese BMI $\geq 40: n(\%)$ & \\
Comorbidities/medical history: $n(\%)$ & $83(15)$ \\
History of lung disease & $81(15)$ \\
History of heart disease &
\end{tabular}

$n$ number of cases, $S D$ standard deviation, $A S A$ American Society of Anesthesiologists, $B M I$ body mass index $\mathrm{kg} \mathrm{m}^{-2}$

${ }^{\text {a }}$ Cases with missing data excluded

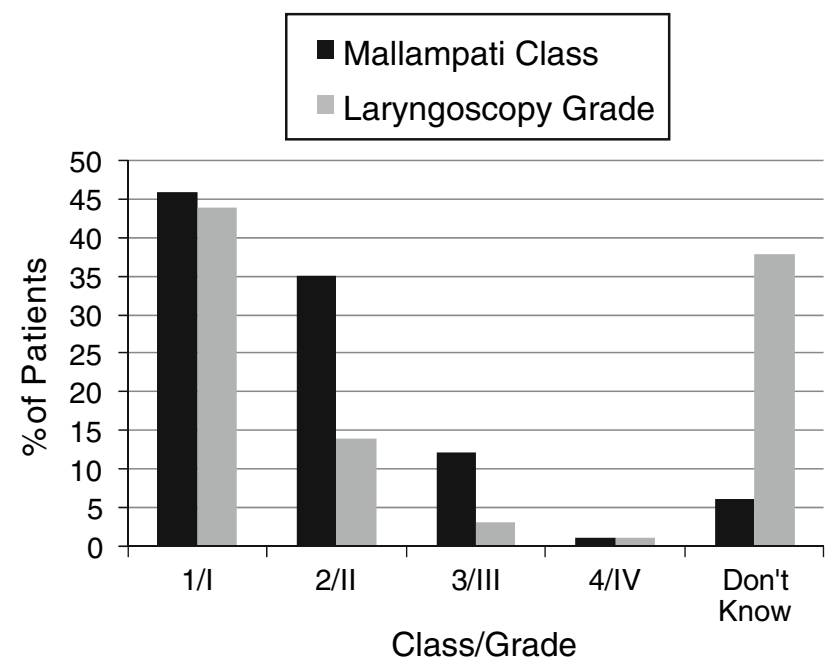

Fig. 2 Airway evaluation

operators, with a median driving pressure of $25 \mathrm{psi}$ (range $8-55 \mathrm{psi}$ ) and a median respiratory rate of $20 \mathrm{bpm}$ (range 10-100 bpm).

The incidence of intraoperative complications was low, with no documented cases of barotrauma, laryngospasm, or submucosal injection of air. The $\mathrm{CO}_{2}$ laser was used safely in 282 patients $(51 \%)$, with no cases of tube ignition or airway fire.

The Hunsaker tube was exchanged in 15 cases for a standard or laser-safe ETT (Table 2). In most of these cases, the exchange was prompted by actual or impending
Table 2 Factors associated with endotracheal tube changes

\begin{tabular}{|c|c|}
\hline Total tube changes $(n, \%)$ & $15(100)$ \\
\hline Hypoxia and/or hypercarbia $(n, \%)$ & $8(53)$ \\
\hline Impending hypoxia and/or hypercarbia $(n, \%)$ & $3(20)$ \\
\hline Surgical request $(n, \%)$ & $3(20)$ \\
\hline Bleeding $(n, \%)$ & $1(7)$ \\
\hline Duration of case $(\min )^{a}$ & $99 \pm 47$ \\
\hline Time of tube change (min from case start) & $55 \pm 33$ \\
\hline
\end{tabular}

hypoxia, hypercarbia, or both. In one case, the Hunsaker tube became obstructed (possibly kinked) two and a half hours into the procedure, resulting in decreased oxygen saturations. In another case, increased bleeding ensued, and there was fear of seeding of blood down the trachea. In the remaining cases, the reasons for the surgeons requesting a tube change were not documented. Tube exchange occurred with greater frequency in prolonged cases.

Hypoxia and hypercarbia were the most common complications in this study. Risk factors included a history of heart disease, older age, an ASA physical status of III or $\mathrm{IV}$, and previous laryngeal surgery (Table 3 ). There was no correlation with a history of lung disease or obesity. All cases of hypoxia occurred when the inspired oxygen level was decreased to $\leq 40 \%$ for the purpose of using the laser. The diagnosis was confirmed in seven hypercarbic patients when arterial blood gases were taken. Only one anesthesia record provided sufficient data to calculate an (A-a) $\mathrm{CO}_{2}$ gradient that was $11 \mathrm{mmHg}$.

One patient experienced stridor immediately after tracheal extubation at the conclusion of surgery. Reexamination under anesthesia showed an edematous right vocal cord that necessitated tracheal reintubation and transfer to the PACU while breathing spontaneously through the endotracheal tube. There were no other postoperative respiratory or cardiovascular complications in the PACU.

\section{Discussion}

Several studies compared different modes of ventilation used during laryngeal surgery. ${ }^{5,7,11}$ The major aim of all techniques has been to provide airway control and safe and effective ventilation with minimal obstruction of the surgical view and optimal access to the operative site.

Subglottic jet ventilation during laryngoscopy has been used since the mid 1970s. It is more efficient than supraglottic ventilation, not only providing ventilation in the trachea rather than above the vocal cords, but also venting blood and debris upwards and outwards with the expiratory flow of air, instead of propelling material further down the 
Table 3 Factors associated with hypoxia and/or hypercarbia

\begin{tabular}{llrr}
\hline Factor & $\begin{array}{l}\text { Hypoxia and/or hypercarbia occurred } \\
(n=26)\end{array}$ & \multicolumn{1}{l}{$\begin{array}{l}\text { No hypoxia and no hypercarbia } \\
(n=505)\end{array}$} & $\begin{array}{l}P \text { value } \\
\text { Age: mean (SD) }\end{array}$ \\
ASA 3/4 & $56(16)$ & $48(17)$ & 0.009 \\
History of cardiac disease $(n, \%)$ & $10(38 \%)$ & $66(17 \%)$ & 0.015 \\
History of previous laryngeal surgery $(n, \%)$ & $23(88 \%)$ & $347(70 \%)$ & $<0.001$ \\
\hline
\end{tabular}

$P$ values by Student's $t$-test (age) and by Fisher's Exact Test (ASA, cardiac disease, and previous laryngeal surgery). There were no differences between patients experiencing hypoxia and/or hypercarbia and other patients in any other factors analyzed (case duration, gender, obesity, history of lung disease). Missing data excluded

ASA American Society of Anesthesiologists Physical Status Classification

tracheobronchial tree. In addition, from the surgical perspective, subglottic jet ventilation causes minimal movement of the vocal cords compared with supraglottic modalities, facilitating visualization and operative access. The major complication is barotrauma due to raised intrathoracic pressure resulting either from obstruction to air outflow or from excessive inspiratory pressures. ${ }^{7,8,12,13}$ Several different tubes for subglottic jet ventilation have been designed over the years, but all have had limitations, including malalignment of the tube, resulting in mucosal injection and inadequate ventilation; inability to monitor airway pressures, resulting in barotrauma (presenting as subcutaneous emphysema, pneumothorax, or pneumomediastinum), and airway fire with laser use. ${ }^{3}$ The Hunsaker Mon-Jet tube has resolved many of these problems.

Previous studies investigating subglottic jet ventilation for laryngeal surgery using the Hunsaker Mon-Jet tube consisted of fewer cases (36 and 84 patients, respectively) and focused primarily on the safety of the device in terms of adequate ventilation. ${ }^{9,14}$ Patel and Rubin published two papers examining subglottic ventilation but focused on its use in 142 patients with uncomplicated airways (Grade I laryngoscopic view $)^{15}$ and 89 patients with difficult airways (50\% airway occlusion or Grade II with cricoid pressure and/or Grade III laryngoscopic view). ${ }^{16}$

This retrospective study of 552 patients represents the cumulated experience from a large clinical series and demonstrates the versatility of this technique across a broad spectrum of patients. It has been a valuable procedure for children, for the elderly, and for increasingly sick patients (six ASA IV and 89 ASA III patients) undergoing uneventful laryngeal surgery. We have successfully used this technique in surgery lasting for up to $4 \mathrm{~h}$, which is considerably longer than other studies, and, contrary to previous concerns, we have safely used this procedure in morbidly obese patients and in patients with poor chest compliance.

In concordance with Patel, ${ }^{16}$ we have demonstrated that this technique can be used effectively in patients with difficult or partially occluded airways, with tracheal intubation being achieved under direct visualization by either the anesthesiologist or the laryngologist. This is of particular benefit in the setting of bilateral vocal cord immobility, large vocal cord lesions, chronic obstructive pulmonary disease (COPD), and where patients have previously undergone radiotherapy with associated airway edema and neck rigidity. In these situations, limiting laryngeal edema is important for a smooth postoperative course without worsened airway distress. A standard endotracheal tube (ETT) in an abnormal airway can cause edema and increase the potential need for tracheostomy. The Hunsaker tube is less likely to cause edema and, consequently, it may be superior to a standard ETT in the marginal airway.

Our findings re-affirm earlier work regarding the safety and efficacy of the Hunsaker Mon-Jet catheter in conjunction with an automatic jet ventilator. ${ }^{3,9}$ Orloff et al. ${ }^{14}$ utilized manual jet ventilation in their series of 84 patients and reported no complications, but $\mathrm{Cook}^{8}$ reported barotrauma and a fatal complication associated with manual subglottic jet ventilation. Manual ventilation does not take advantage of one of the most important features of combining the Hunsaker tube with automatic jet ventilationreducing the risk of barotrauma. We recommend the use of a dedicated automatic jet ventilator that has an automatic shut-off if airway pressures exceed preset limits. Also, this sensitive system alerts the clinician to tube kinking during the procedure by triggering the high inspiratory pressure alarm allowing for rapid resolution of the underlying problem.

One limitation of this study and any retrospective study is the issue of missing data compromising the accurate interpretation of results. The advent of electronic recordkeeping will reduce this problem in future studies. The anesthesia records included in our database were all handwritten with vital signs recorded at intervals no less frequently than every $5 \mathrm{~min}$. We lacked ventilation data (driving pressure and respiratory rate) in many patients, but it is likely that most of the observed cases of hypoxia and 
hypercarbia resulted from hypoventilation. The "open" breathing system results in lower, less accurate $\mathrm{ETCO}_{2}$ data that can provide misleading information regarding the adequacy of ventilation. Lung disease and obesity were not risk factors for hypoxia and hypercarbia in this study, but, due to poor lung or chest compliance, these patients often require higher driving pressures to achieve effective ventilation. Arterial blood gases taken from seven hypercarbic patients did confirm high arterial $\mathrm{CO}_{2}$ levels. The one (A-a) $\mathrm{CO}_{2}$ gradient of $11 \mathrm{mmHg}$ with sufficient data to calculate gradients corresponds with the average $(\mathrm{A}-\mathrm{a}) \mathrm{CO}_{2}$ gradient of $10-12 \mathrm{mmHg}$ calculated by Orloff in her prospective study of 84 patients. ${ }^{14}$

Although heart disease was found to be a significant risk factor for hypoxia and/or hypercarbia, we did not specifically analyze intraoperative cardiovascular variables, as it was impossible to deduce from the anesthesia records whether variances in heart rate and blood pressure were secondary to surgical stimulation, alterations in the depth of anesthesia, the effects of jet ventilation, or a combination of the foregoing factors. However, we did not observe any perioperative cardiovascular complications.

The Hunsaker Mon-Jet tube was exchanged for a standard or laser ETT at the discretion of the anesthesia provider. Differences could not be established from the records between the patients with hypoxia and/or hypercarbia whose tubes were exchanged and those whose tubes were not exchanged. In all cases of hypoxia and/or hypercarbia, tube exchange, alteration of ventilation parameters, or an increase in inspired oxygen resulted in resolution of the problem (evidenced by documentation of improved oxygenation and/or lower $\mathrm{ETCO}_{2}$ ) and facilitated successful conclusion of surgery.

There are several technical and anesthetic "pearls" from these data that can facilitate safe and effective use of the Hunsaker Mon-Jet tube and jet ventilator. When inserting the Hunsaker Mon-Jet tube, the distal end should be passed 6-7 $\mathrm{cm}$ below the glottis to ensure that the airway pressure monitoring port is beyond the vocal cords (Fig. 3). Blind attempts at insertion should be avoided, since jet ventilation to the esophagus could cause tissue damage and even perforation. Before inserting the surgical laryngoscope and at any time it is removed for more than a few seconds, an oral airway should be placed in the mouth to allow egress of inspired air to prevent barotrauma. To avoid the weight of the lines kinking the tube, it should be secured at the corner of the mouth with the ventilator lines supported (Fig. 4). Changes in the waveform of the capnograph often indicate slight kinking of the tube, while complete obstruction/kinking of the tube will cause automatic shutdown of the ventilator. The position of the tube should be checked regularly to ensure that it has not been dislodged during surgical manipulation of the airway. To allow

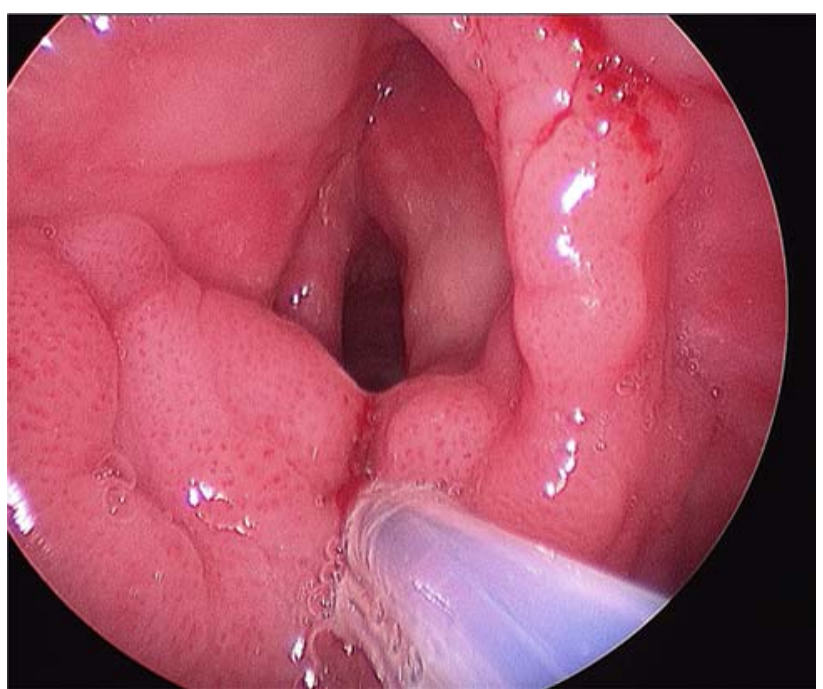

Fig. 3 View of a Hunsaker Mon-Jet tube in the glottis providing unobstructed access to the laryngeal pathology to be surgically treated

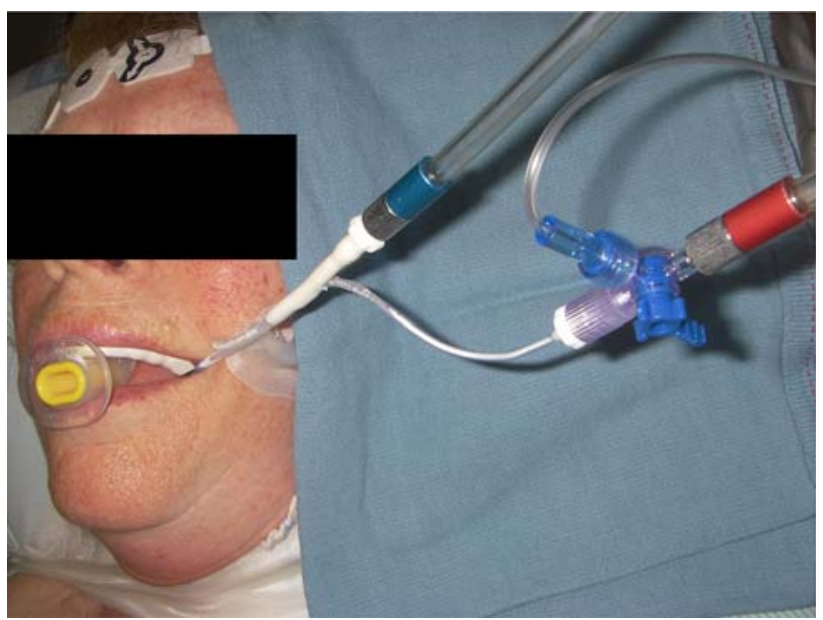

Fig. 4 View of a Hunsaker Mon-Jet tube secured at the corner of a patient's mouth with jet ventilator tubing suspended to prevent kinking. Note the oral airway to allow egress of air when the rigid laryngoscope is not in use

adequate time for full chest recoil and expiration of inspired air, we suggest that the inspiratory:expiratory ratio should not exceed 1:2. The ventilator settings can be adjusted according to observed chest excursion, recoil, and the $\mathrm{ETCO}_{2}$ trend, which are indicators of adequacy of ventilation. The $\mathrm{ETCO}_{2}$ sampling line is attached to the side arm of the stopcock (Fig. 4), and since the airway pressures will appear lower if the $\mathrm{ETCO}_{2}$ is continuously open, thus compromising the safety of the device, sampling should be intermittent.

From our experience, total intravenous anesthesia (TIVA) combined with neuromuscular relaxation provides optimal anesthetic conditions. To minimize coughing and laryngospasm at the end of the case, the vocal cords can be 
sprayed with $4 \%$ lidocaine. When faced with an anticipated or known difficult airway, standard airway algorithms should be applied.

In 1994, Hunsaker improved on a novel airway device for subglottic ventilation that addressed the major concern of barotrauma, which had previously been an issue with this ventilatory mode and other airway devices. ${ }^{3}$ Our series confirms Hunsaker's premise that the Hunsaker Mon-Jet tube, in conjunction with an automatic jet ventilator, is a safe subglottic tube that minimizes the risk of barotrauma. This technique provides surgeons with an essentially unobstructed view of the larynx and a laser-safe environment. Anesthesiologists who manage patients with either easy or difficult airways for this type of airway surgery should consider incorporating this technique in their clinical practice.

Acknowledgements The authors acknowledge the assistance of Viet Nguyen in the preparation of the MS3 database and appreciate the support and editorial review from Brian K. Ross, PhD MD.

Conflicts of interest None declared.

\section{References}

1. Sanders $R D$. Two ventilating attachments for bronchoscopes. Del Med J 1967; 39: 170-5.

2. Rajagopalan $R$, Smith $F$, Ramachandran PR. Anaesthesia for microlaryngoscopy and definitive surgery. Can Anaesth Soc J 1972; 19: 83-6.

3. Hunsaker $D H$. Anesthesia for microlaryngeal surgery: the case for subglottic ventilation. Laryngoscope 1994; 104(8 Pt 2 suppl 65): $1-30$.

4. Rezaie-Majd A, Bigenzahn W, Denk D-M, et al. Superimposed high-frequency jet ventilation (SHFJV) for endoscopic laryngotracheal surgery in more than 1500 patients. Br J Anaesth 2006; 96: 650-9.
5. Bacher A, Lang T, Weber J, Aloy A. Respiratory efficacy of subglottic low-frequency, subglottic combined-frequency, and supraglottic combined-frequency jet ventilation during microlaryngeal surgery. Anesth Analg 2000; 91: 1506-12.

6. Ihra G, Gockner G, Kashanipur A, Aloy A. High-frequency jet ventilation in European and North American institutions; developments and clinical practice. Eur J Anaesthesiol 2000; 17: 418-30.

7. Jaquet Y, Monnier P, Van Melle G, Ravussin P, Spahn DR, Chollet-River M. Complications of different ventilation strategies in endoscopic laryngeal surgery: a 10-year review. Anesthesiology 2006; 104: 52-9.

8. Cook TM, Alexander R. Major complications during anaesthesia for elective laryngeal surgery in the UK: a national survey of the use of high-pressure source ventilation. Br J Anaesth 2008; 101: 266-72.

9. Brooker CR, Hunsaker DH, Zimmerman AA. A new anesthetic system for microlaryngeal surgery. Otolaryngol Head Neck Surg 1998; 118: 55-60.

10. Cormack RS, Lehane J. Difficult tracheal intubation in obstetrics. Anaesthesia 1984; 39: 1105-11.

11. Bacher A, Pichler K, Aloy A. Supraglottic combined frequency jet ventilation versus subglottic monofrequent jet ventilation in patients undergoing microlaryngeal surgery. Anesth Analg 2000; 90: 460-5.

12. Shikowitz MJ, Abramson AL, Liberatore L. Endolaryngeal jet ventilation: a 10-year review. Laryngoscope 1991; 101: 455-61.

13. Oliverio $R \mathrm{Jr}$, Ruder CB, Fermon C, Cura A. Pneumothorax secondary to ball-valve obstruction during jet ventilation. Anesthesiology 1979; 51: 255-6.

14. Orloff LA, Parhizhar N, Ortiz E. The Hunsaker Mon-Jet ventilation tube for microlaryngeal surgery: optimal laryngeal exposure. Ear Nose Throat J 2002; 81: 390-4.

15. Rubin JS, Patel A, Lennox P. Subglottic jet ventilation for suspension microlaryngoscopy. J Voice 2005; 19: 146-50.

16. Patel A, Rubin JS. The difficult airway: the use of subglottic jet ventilation for laryngeal surgery. Logoped Phoniatr Vocol 2008; 33: $22-4$. 